\title{
Pseudomembranous enterocolitis cured with three intestinal microbiota transplantations
}

\author{
Álvaro Zamudio-Tiburcio*, Héctor Bermúdez-Ruiz, Pedro Antonio Reyes-López, Gonzalo de la Torre-Martínez and Andrés Pareja- \\ Ramírez \\ Department of Medicine and Surgery, AOU St. John of God and Ruggi of Aragon, Liver Following Transplantation Center, University of Salerno, Italy
}

\section{Summary}

We present a unique case of a 82 years old women, with this newly described condition called "pseudomembranous enterocolitis cured with three transplants of intestinal microbi0ta (imt)." We evaluated the case of gaw, who had a perforates sigmoid diverticulum $10 \mathrm{~m}$ days ago and had surgery with sigmoid resection, colostomy and hartmann's pouch. Her progress was good. However, she was given metronidazole and vancomycin, antibiotics that caused severe diarrhea and toxic state, a week postoperatively. Histopathological study of surgical specimen showed colonic mucosa extensively ulcerated and granulation tissue, fibrin and abundant neutrophils. Submucosal edema and acute periserositis. The muscular and mucosal layer had not alterations. A diagnosis of pseudomembranous enterocolitis (pm) was made. The patient had a toxic state, semi-conscious, diaphoretic and extensive erythema in the right forearm, with minor erythema at the left forearm and face, as well as perineal erythema, third degree edema in lower limbs, dehydrated and chest $\mathrm{x}$-ray showed interstitial pneumonitis. She had a typical case of $\mathrm{pm}$, and proceeded to perform an intestinal microbiota transplantation (imt) from healthy donors at clinical and laboratory studies. After that imt we performed colonoscopy, which showed at the course of transverse and right colon multiple plaques of whitish, cotton-like appearance, which protuded on the mucosal surface. This appearance were also seen at the left colon. We applied $400 \mathrm{ml}$. Of imt in the right colon and $100 \mathrm{ml}$ at the hartmann's pouch of rectum. At the colonoscopy we placed a foley's catheter with an inflated balloon $20 \mathrm{ml}$. Also, solid petroleum jelly was left to prevent imt elimination. We removed all antibiotic treatment and replaced with probiotics, through the nasogastric tube.

Three day later the patient had a better general condition, was conscious, with erythema limited to forearms, face and perineum, the lowers limb had no edema and she was better hydrated.

The second imt was performed with another $400 \mathrm{ml}$. Of microbiota in right colon and $100 \mathrm{ml}$. At the hartmann's pouch. To prevent imt a $20 \mathrm{ml}$. Inflated balloon colostomy (foley's catheter) sealed with solid petroleum jelly.

Three days later, a new imt was required under the same conditions as the former two imt. On this occasion the patient was fully aware, speaking and responded correctly to our questions. She had no erythema in her body, no edema at her legs and her chest x-ray had no pneumonitis, and showed only a small leak at the base of right lung.

Further treatment without antibiotics, was with symbiotic by mouth and was under another treating team.

We reviewed the literature, and we hope to encourage colleagues to use this procedure, which had similar results in the world.

\section{Presentation of the case}

Gaw, female, 82 years old with a history of sigmoid diverticulum perforation, peritonitis treated with sigmoid resection, colostomy and hartmann's pouch were given the following antibiotics: metronidazole, vancomycin which caused pseudomembranous enterocolitis. the patient required 3 intestinal healthy microbiota transplantations to showed improvement, both at clinical and colonic mucosacolonsoscopy visualized-until total remission. Histopathologic studies showed extensive ulcerated colonic mucosa with granulation tissue, fibrin and abundant polymorfonulcear cells and, submucosal edema, acute peri-serositis without muscular and mucosal alterations viable resection margins.

Diagnosis: Pseudomembranous enterocolitis (Figures 1-6).

\section{Discussion}

The main conditions that is treated with imt is clostridium difficile infection, as well as recurrence [1]. Eisman et al. [2] were the first to carry out this procedure with good results. since them, numerous cases have been described in the world literature, many doctors performed imt successfully, broody [3-8] observed that a second or in needed third transplantation is necessary to get good results, just as happened in our patient. Broody not only directed his attention to $C$. difficile, goes a little further and used imt in irritable bowel syndrome, myoclonusdystonia, ulcerative colitis and chronic fatigue syndrome [9].

Numerous authors joint on the imt, drekonia confirms positive results [10] and showed a pair of randomized controls. studying series of 28 and 5 cases, detected a recurrence in 2 patients, it concludes that imt may have a significant effect with a few short-term adverse effects for recurrent CDI. Evidence in insufficient on $\mathrm{ft}$ for refractory or initial CDI treatment and weather not effects vary by donor, preparation or delivery method. Felipe moscoso in Chile points out the incomparable experience with a case in which he performed the procedure, with excellent results in a 53 years old woman. observed in its revision up to $90 \%$ of cure [11-14]. The case presented was one of the two analyzed, with recurrence of the infectious process.

Moayyedi in Australia also performs a randomized study with promising results in the reviewed literature [15].

Correspondence to: Álvaro Zamudio-Tiburcio, Private consultation. Colonia Portales Norte. Benito juarez delegation. C. P. 03300. Mexico City, Mexico, Tel: +52 (55) 2155-3877; E-mail: alzati58@hotmail.com

Received: December 14, 2017; Accepted: December 20, 2017; Published: January 03, 2018 

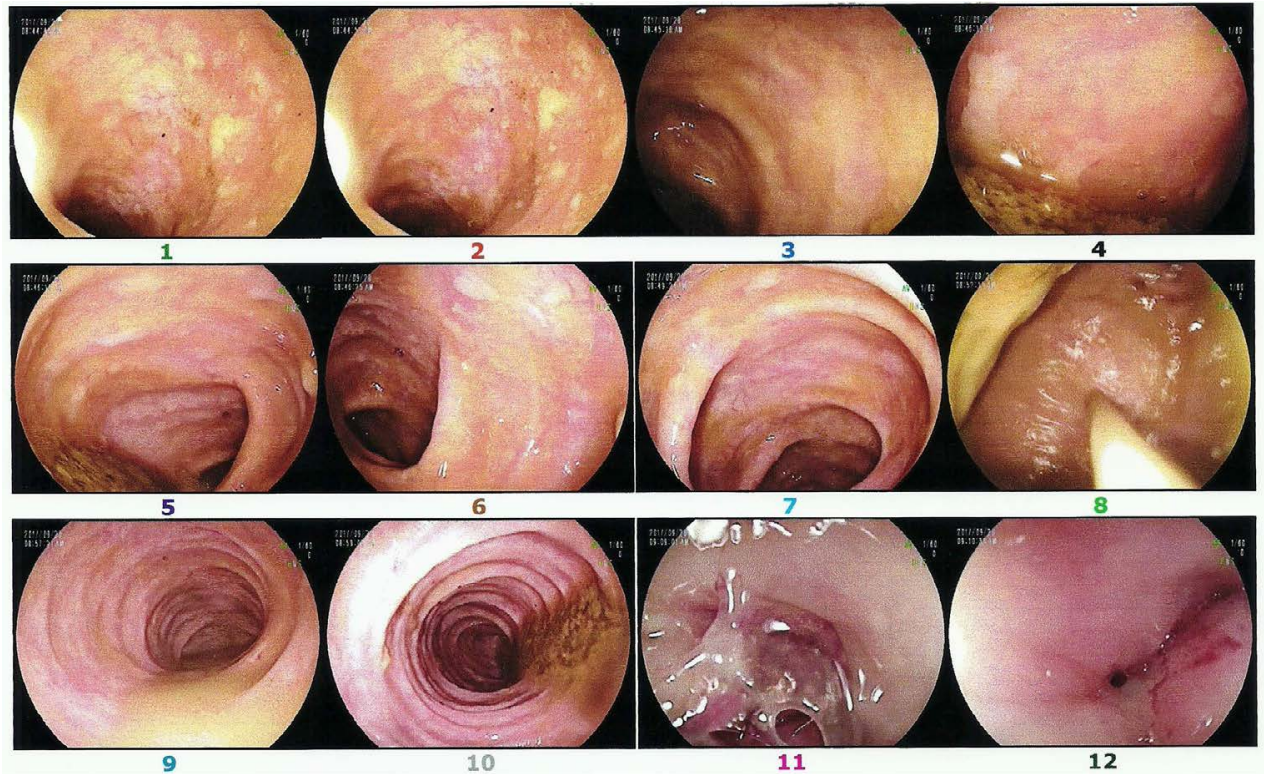

Figure 1. First Transplant. Throughout the course of the transverse and right colon were observed multiple plaques of whitish, cotton-like appearance. They protrude to the surface of the mucosa. The same happens in the left colon.

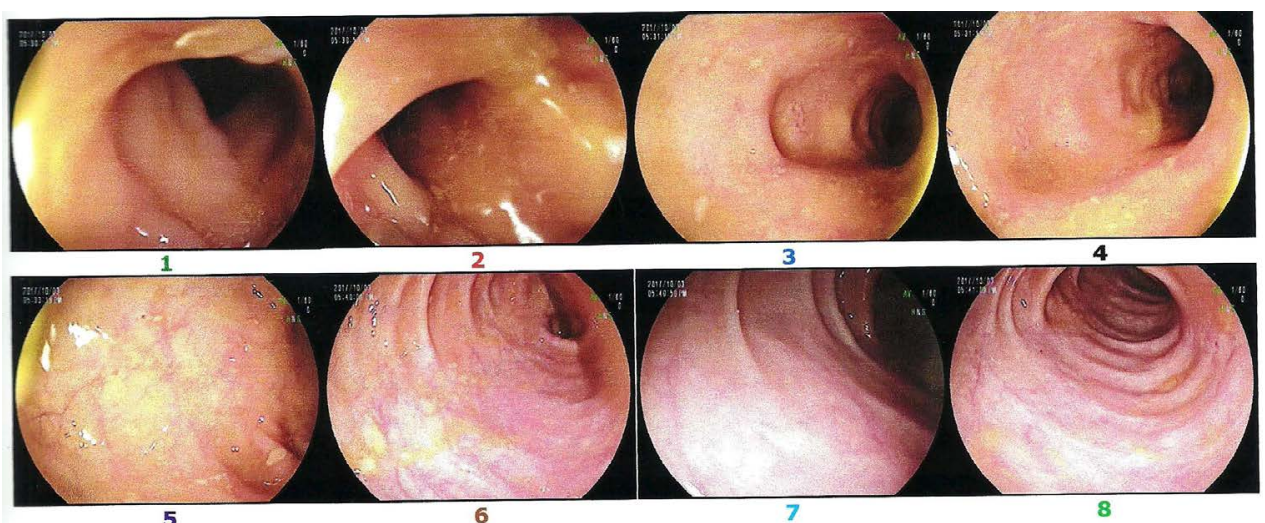

Figure 2. Third Transplant. The transverse and right colon are normal.

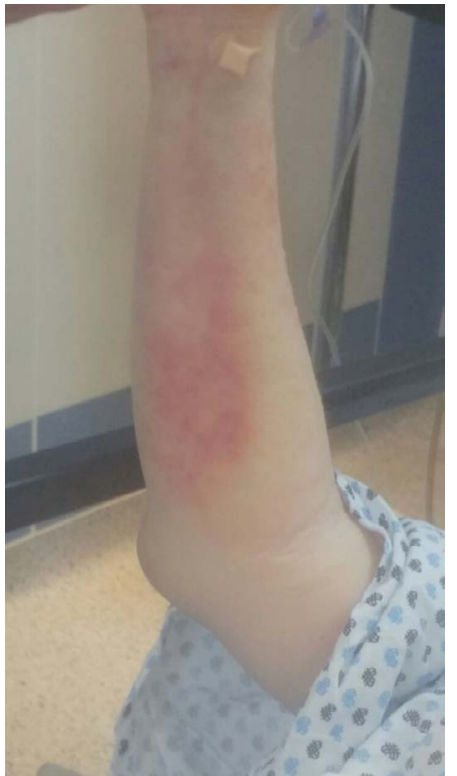

Figure 3. Large erythema in right forearm.

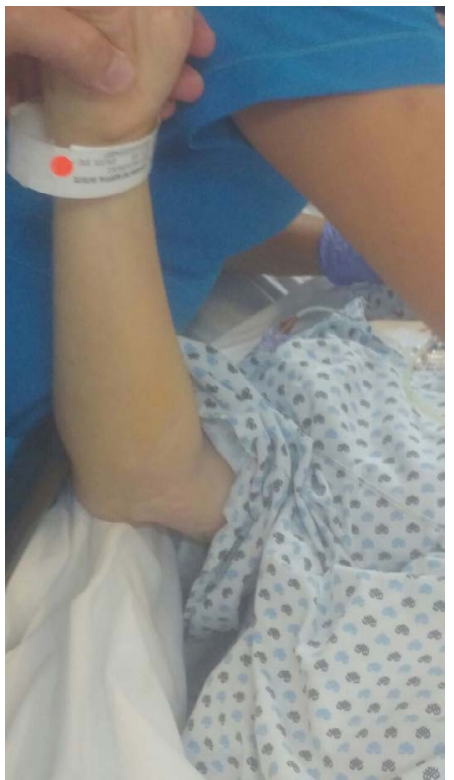

Figure 4. The erythema has disappeared. 


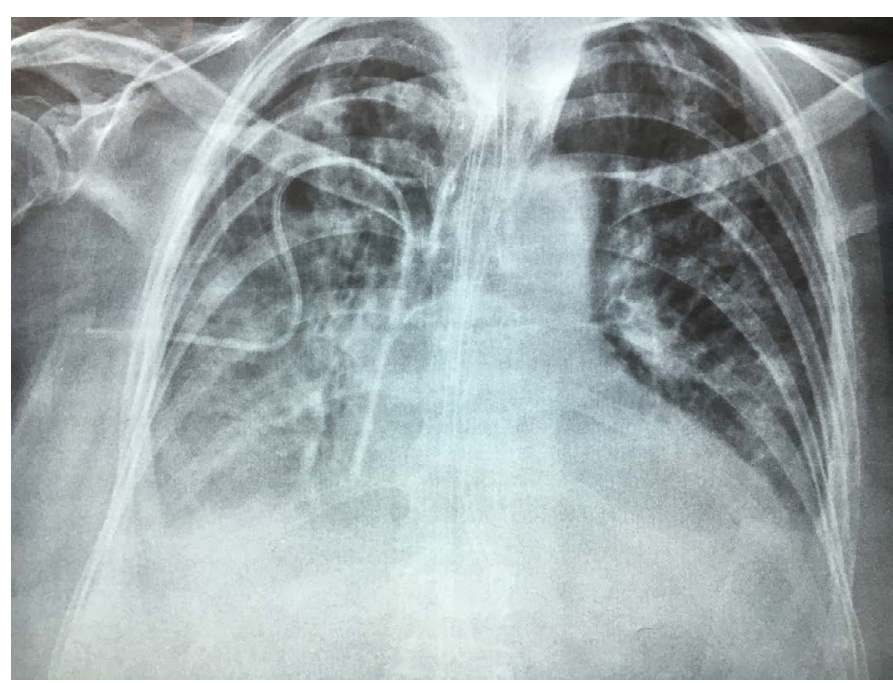

Figure 5. The chest X-ray shows right basal opacity, with atelectasis lines.

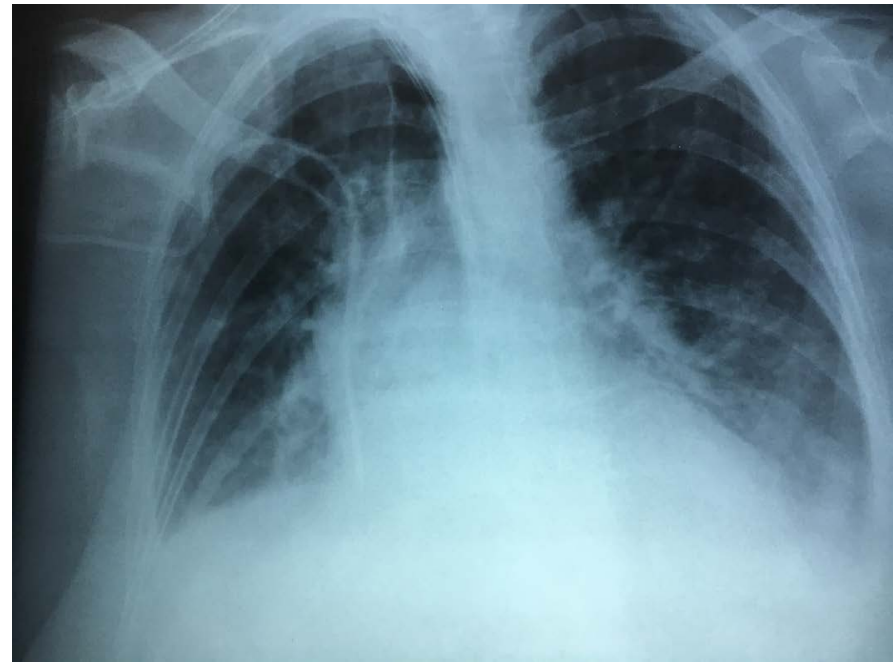

Figure 6. Radiographic control (post-transplant has improved substantially). Only discreet right basal effusion.

Espinosa, also in Chile [16] reports that the first case of imt due to $C$. difficile, with good results and its review of literature finded relapse by bacteria reaches up to $30 \%$, after the first episode. It is observed patients with crohn's disease and recurrent cd infection who presented after fecal transplant $E$. coli bacteremia, suggesting the need for caution in the use of this strategy. E. coli bacteremia and two episodes of 10 months after the fmt diarrhea due to cd infection, treated with vancomycin with good clinical response. Although acceptance by the health staffs is not total, studies have shown that most patients with ulcerative colitis are interested in considering imt as part of the therapeutic strategy of their disease [17].

Undoubtedly, the most important aspect in imt is the selection of the donor, an excellent determination of who provide microbiota, coupled with a compete medical history, exhaustive and directed to communicable pathologies and, determining the studies necessary to avoid the infecting the patient with a new disease, determine to a large extent the success of the transplant [18-20].

Zipursky et al. as well as Gough, [21,22] address the issue of recurrence. they point out that the imr is safe and effectively used when conventional handling fails. they note that the solution of the disease occurs in about $92 \%$, with adverse effects being uncommon and deaths are not usually due to the process, but parallel problems. The favorable changes that appear in the microbiota after transplantation have been documented [23-25], imt is one of the most commonly used procedures as emergency treatment for $C$. difficile infection, being imposed on other systems such as the use of monoclonal antibodies directed against toxin a and b, C. difficile vaccination [26]. imt is increasingly adopted by groups that treat patients with $C$. difficile infection, since the cure is more than $90 \%$, as reported in multiple centers. in the procedure it is preferred to use the upper and lower digestive tract, through the rectum, using endoscope, since on the other hand it is visualized and corroborates the diagnosis, on the other hand, it can show some other pathologies and if possible treat them [27-29]. Although until recently the imt was very questions, at present no group is opposed. they accept it and more centers use it. When they went, only 150 cases the questioning was severe [30]. Now, with hundreds of patients usefully treated, few institutes do not recommend imt and its benefit $[31,32]$.

\section{Conclusion}

It is confirmed once again that the most favorable treatment, when the conventional methodology in $C$. difficile infection fails, is the intestinal microbiota transplantation. Sometimes it is necessary to carry out up to three transplants to obtain good results, as there was need to do so, in the present case. The response is usually immediate or, well at the end of the third transplant. given the excellent results of imt, we encouraged other author to carry out this procedure, minimally invasive and with highly reliable results as positive percentages, above $95 \%$.

\section{References}

1. Eisman B, Silen W, Bascom GS, Kauvar AJ (1958) Fecal enema as an adjunct in the treatment of pseudomembranous enterocolitis. Surgery 44: 854-859. [Crossref]

2. Reid G, Younes JA, Van der Mei HC, Gloor GB, Knight R, et al. (2011) Microbiota restoration natural and supplemented recovery of human microbial communities. Nat Rev Microbiol 9: 27-38. [Crossref]

3. Borody TJ, Paramsothy S, Agrawal G (2013) Fecal Microbiota Transplantation Indications, Methods, Evidence and future Direction. Curr Gastroenterol 15: 337. [Crossref]

4. Borody TJ, Warren EF, Leis S, Surace R, Ashman O (2003) Treatment of Ulcerative colitis using fecal bacteriotherapy. J Clin Gastroenterol 37: 42-47. [Crossref]

5. Borody TJ, George L, Andrews P, Brandt S, Noonan S, Cole P, et al. (1989) Bowelflora alteration a potential cure for inflammatory bowel disease and irritable bowel syndrome? Med J Aust 150: 604. [Crossref]

6. Borody TJ, Khoruts A (2012) Fecal microbiota transplantation and emerging applications. Nat Rev Gastroenterol Hepatol 9: 88-96. [Crossref]

7. Borody TJ, Rosen D, Torres J, Campbell J, Nowak A (2011) Myoclonus-dystonia (MD) mediated by GI microbiota diarrhoea treatment improves M-D symptoms. Am J Gastroenterol: 106.

8. Borody TJ, Finlayson S (2013) The GI microbiome and its role in chronic fatigue syndrome: A summary of bacteriotherapy. J Aust Coll Nutr Env Med 31: 3-8.

9. Giloteaux L, Goodrich JK, Walters WA, Levine SM, Ley RE, et al. (2016) Reduced diversity and altered composition of the gut microbiome in individuals with myalgic encephalomyelitis/chronic fatigue syndrome. Microbiome 4: 30 .

10. Drekonia D, Reich J, Gezahegn S, Greer N, Shaukat A, et al. (2015) Fecal Microbiota Transplantation for Clostridium difficile Infection: A Systematic Review. Ann Intern Med 162: 630-638. [Crossref]

11. Moscoso F, Simian D, Rivera D, Acuña G, Quera R (2015) Fecal microbiota transplantation in recurrent Clostridium difficile infection. Report of one case. Rev Med Chile 143: 531-535. [Crossref]

12. Kelly CP, La Mont JT (2008) Clostridium difficile-more difficult than ever. $N$ Engl $J$ Med 359: 1932-1940.

13. Cammarota G, Ianiro G, Bibbò S, Gasbarrini A (2014) Fecal Microbiota Transplantation: A New Old Kid on the Block for the Management of Gut Microbiota-related Disease. $J$ Clin Gastroenterol 48: S80- S84. [Crossref] 
14. Youngster I, Sauk J, Pindar C, Wilson RG, Kaplan JL, et al. (2014) Fecal microbiota transplant for relapsing Clostridium difficile infection using a frozen inoculum from unrelated donors: a randomized, open-label, controlled pilot study. Clin Infect Dis 58: 1515-1522. [Crossref]

15. Moayyedi P, Yuan Y, Baharith H, Ford AC (2017) Faecal microbiota transplantation for Clostridium difficile-associated diarrhoea: a systematic review of randomized controlled trials. Med J Aust 207: 166-172. [Crossref]

16. Espinoza R, Quera R, Meyer L, Rivera D (2014) Fecal microbiota transplantation: first case report in Chile and review. Rev Chilena Infectol 31: 477-482. [Crossref]

17. Kahn S A, Vachon A, Rodríguez D, Goppingen SR, Surma B, et al. (2013) Patients perceptions of fecal microbiota transplantation for Ulcerative colitis. Inflamm Bowel Dis 19: 1506-1513. [Crossref]

18. Zamudio TA, Bermúdez RH, Lezama GH, Guevara OM, Solares EI, et al. Breaking paradigms. Intestinal microbiota transplant. Preliminar report. Cir Cir 85: 6-12. [Crossref]

19. Zamudio TA, Bermúdez RH, Guevara AM, Lezama GR, Solares EI, et al. (2017) Transplantation of Intestinal Microbiota and its Clinical Application. EC Microbiology 7: 198-208.

20. Zamudio TA, Bermúdez RH (2017) Microbioma and Cancer. EC Microbiology 9: 207-213.

21. Zipursky JS, Sidorsky TI, Freedman CA, Sidorsky MN, Kirkland KB (2012) Patient Attitudes Toward the Use of Fecal Microbiota Transplantation in the Treatment of Recurrent Clostridium difficile Infection. Clin Infect Dis 55: 1652-1658. [Crossref]

22. Gough E, Shaikh H, Manges AR (2011) Systematic Review of Intestinal Microbiota Transplantation (Fecal Bacteriotherapy) for Recurrent Clostridium difficile Infection. Clin Infect Dis 53: 994-1002. [Crossref]
23. Grehan HJ, Borody TJ, Leis SM, Campbell J, Mitchel H, et al. (2010) Durable alteration of the colonic microbiota by the administration of donor fecal flora. $J$ Clin Gastroenterol 44: 551-561. [Crossref]

24. Tvede M, Raik-Madsen J (1989) Bacteriotherapy for chronic relapsing Clostridium difficile diarrhea in six patients. Lancet 1: 1156-1160. [Crossref]

25. Persky SE, Brandt LJ (2000) Treatment of recurrent Clostridium difficile associated diarrhea by administration of donated stool directly through a Colonoscope. Am J Gastroenterol 95: 3283-3285. [Crossref]

26. Geus KD, Elshaboury RH, Holt JS (2013) Fecal Microbiota Transplantation and Emerging Treatment for Clostridium difficile Infection. J Pharm Pract 26: 498-505. [Crossref]

27. Rohlke F, Stollman N (2012) Fecal microbiota transplantation in relapsing Clostridium difficile infection. Therap Adv in Gastroenterol 5: 403-420. [Crossref]

28. Rowan IC (2012) "Poop Transplant" May combat Bacterial Infection. Live Science: $10-20$.

29. Cornely OA, Miller MA, Louie TJ, Crook DW, Gorbach SL (2012) Treatment of first Recurrence of Clostridium difficile infection: Fidaxomicin Versus Vancomycin. Clin Infect Dis. 55: S154-S161. [Crossref]

30. Van Nood E, Speelman P, Kuijper EJ, Keller JJ (2009) Struggling with recurrent Clostridium difficile Infection. Euro Surveill 14: 19316. [Crossref]

31. Owen C, Broussard E, Surawicz C (2013) Fecal microbiota Transplantation and donor standardizations. Trend Microbiol 219: 443-445. [Crossref]

32. Lund-Tonnesen S, Schreiner A, Midtvedt T (1998) Clostridium difficile associated diarrhea treated with homologous feces. Tidsskr Nor Laegeforen 118: 1027-1030. [Crossref]

Copyright: (C2018 Zamudio-Tiburcio A. This is an open-access article distributed under the terms of the Creative Commons Attribution License, which permits unrestricted use, distribution, and reproduction in any medium, provided the original author and source are credited. 